\title{
Diverse Roads to Relapse: A Discriminative Cue Signaling Cocaine Availability Is More Effective in Renewing Cocaine Seeking in Goal Trackers Than Sign Trackers and Depends on Basal Forebrain Cholinergic Activity
}

\author{
○Kyle K. Pitchers, Kyra B. Phillips, Jonte L. Jones, Terry E. Robinson, and \Martin Sarter \\ Department of Psychology and Neuroscience Program, University of Michigan, Ann Arbor, Michigan 48109
}

Stimuli associated with taking drugs are notorious instigators of relapse. There is, however, considerable variation in the motivational properties of such stimuli, both as a function of the individual and the nature of the stimulus. The behavior of some individuals (sign trackers, STs) is especially influenced by cues paired with reward delivery, perhaps because they are prone to process information via dopamine-dependent, cue-driven, incentive salience systems. Other individuals (goal trackers, GTs) are better able to incorporate higher-order contextual information, perhaps because of better executive/attentional control over behavior, which requires frontal cortical cholinergic activity. We hypothesized, therefore, that a cue that "sets the occasion" for drug taking (a discriminative stimulus, DS) would reinstate cocaine seeking more readily in GTs than STs and that this would require intact cholinergic neurotransmission. To test this, male STs and GTs were trained to self-administer cocaine using an intermittent access schedule with periods of cocaine availability and unavailability signaled by a $\mathrm{DS}^{+}$and a DS ${ }^{-}$, respectively. Thereafter, half of the rats received an immunotoxic lesion that destroyed $40-50 \%$ of basal forebrain cholinergic neurons and later, after extinction training, were tested for the ability of noncontingent presentations of the $\mathrm{DS}^{+}$to reinstate cocaine seeking behavior. The $\mathrm{DS}^{+}$was much more effective in reinstating cocaine seeking in GTs than STs and this effect was abolished by cholinergic losses despite the fact that all rats continued to orient to the DS ${ }^{+}$. We conclude that vulnerability to relapse involves interactions between individual cognitive-motivational biases and the form of the drug cue encountered.

Key words: acetylcholine; addiction; basal forebrain; drug cues; relapse; sign and goal trackers

Significance Statement

The most predictable outcome of a diagnosis of addiction is a high chance for relapse. When addicts encounter cues previously associated with drug, their attention may be unduly attracted to such cues and these cues can evoke motivational states that instigate and maintain drug-seeking behavior. Although sign-tracking rats were previously demonstrated to exhibit greater relapse vulnerability to Pavlovian drug cues paired with drug delivery, here, we demonstrate that their counterparts, the goal trackers, are more vulnerable if the drug cue acts to signal drug availability and that the forebrain cholinergic system mediates such vulnerability. Given the importance of contextual cues for triggering relapse and the human cognitive-cholinergic capacity for the processing of such cues, goal trackers model essential aspects of relapse vulnerability.

\section{Introduction}

If cues associated with the administration of drugs of abuse are attributed with incentive salience, they can acquire considerable

\footnotetext{
Received April 12, 2017; revised June 10, 2017; accepted June 16, 2017.

Author contributions: K.K.P., T.E.R., and M.S. designed research; K.K.P., K.B.P., and J.L.J. performed research; K.K.P. and K.B.P. analyzed data; K.K.P., T.E.R., and M.S. wrote the paper.

This work was supported by the U.S. Department of Health and Human Services (Public Health Service Grant P01 DA031656 to T.E.R. and M.S.)

The authors declare no competing financial interests.

Correspondence should be addressed to Martin Sarter, Department of Psychology and Neuroscience Program,

University of Michigan, 530 Church Street, 4030 East Hall, Ann Arbor, MI 48109. E-mail: msarter@umich.edu.
}

control over motivated behavior. For example, they can facilitate ongoing drug-taking behavior and, after a period of abstinence, they can reinstate drug-seeking behavior, producing relapse (Robinson and Berridge, 1993; Milton and Everitt, 2010). There is, however, considerable variation in the extent to which reward cues acquire motivational properties, both across individuals and as a function of the form of the cue itself (Meyer et al., 2012; Robinson et al., 2014; Saunders et al., 2014; Singer et al., 2016). Some rats (sign trackers, STs) are especially prone to attribute 
incentive salience to discrete, localizable food or drug cues paired with reward delivery (conditioned stimuli, CSs), as indicated by their tendency to approach such cues, their willingness to exert effort to obtain them, and the ability of such cues to reinstate reward-seeking behavior. In contrast, goal trackers (GTs) are more likely to approach the location of reward delivery in a Pavlovian conditioned approach task. Interestingly, contextual cues gain greater control over behavior in GTs than STs, as indicated by greater cocaine context-induced hyperactivity, greater context-induced renewal of cocaine seeking behavior (Saunders et al., 2014), and greater context fear conditioning (Morrow et al., 2011).

These studies have led to the idea that different individuals process motivationally salient information in different ways and by different neural systems (Clark et al., 2012; Robinson et al., 2014; Flagel and Robinson, 2017) and thus may be sensitive to different "triggers" of relapse. Discrete cue-dominated behavior in STs is dopamine (DA) dependent (Flagel et al., 2011; Saunders and Robinson, 2012), associated with poor top-down executive control over behavior (Paolone et al., 2013), action impulsivity (Lovic et al., 2011), and relatively unresponsive cholinergic signaling in cortex (Koshy Cherian et al., 2017). This may all reflect a dominance of "bottom-up" motivational control over behavior in STs. In contrast, GTs appear to use more cognitive or top-down analyses of the stimulus situation that are not DA dependent. Consistent with the hypothesis that elevated cholinergic capacity in GTs mediates top-down control, attenuation of cholinergic activity increases the propensity for sign tracking (Koshy Cherian et al., 2017). Top-down biases in GTs may involve so-called "model-based" processes that more readily incorporate higher-order information such as changes in context and lead to explicit cognitive expectations of reward (Flagel et al., 2009; Clark et al., 2012).

In addition to discrete CSs, a class of cues that is very important in producing craving and relapse in addicts are those that signal drug availability, or "set the occasion" for drug taking (Crombag et al., 2008). Occasion setters or, in operant parlance, discriminative stimuli (DS), are potent instigators of relapse even after very long periods of abstinence (Weiss et al., 2000). Such stimuli are thought to exert higher-order hierarchical control over behavior (Rescorla, 1988) and are also thought to share many properties of contextual stimuli (Weiss, 2005; Trask et al., 2017). We hypothesized, therefore, that a $\mathrm{DS}^{+}$signaling cocaine availability would reinstate cocaine seeking behavior more readily in GTs than STs. Furthermore, we hypothesized that interfering with cortical cholinergic neurotransmission would interfere with $\mathrm{DS}^{+}$-evoked cocaine seeking in GTs, but given that this system is very unresponsive in STs, they may be relatively immune to a cholinergic manipulation. These hypotheses were tested using an intermittent access (IntA) cocaine self-administration procedure in which a $\mathrm{DS}^{+}$predicted drug availability and a DS ${ }^{-}$drug unavailability (Zimmer et al., 2012; Kawa et al., 2016). After extinction, the ability of noncontingent presentation of the $\mathrm{DS}^{+}$to reinstate cocaine-seeking behavior was assessed in STs and GTs with or without cholinergic losses. The results support our hypotheses and emphasize that STs and GTs may model different vulnerabilities for addiction, which is important given that, in the "real world," drug users with different psychological/cognitive "styles" encounter diverse kinds of drug cues that can trigger cravings and expectations via different cognitive and neuronal mechanisms.

\section{Materials and Methods}

Animals

A total of 128 Sprague Dawley rats (Envigo) were used. Rats weighed 250-275 g upon arrival and were individually housed in Plexiglas cages on a $12 \mathrm{~h}$ light $/ 12 \mathrm{~h}$ dark cycle (lights on at $0800 \mathrm{~h}$ ), with regulated temperature and humidity. We previously reported that the expression of the ST/GT phenotype in Sprague Dawley and heterogeneous stock rats is not affected by sex (Pitchers et al., 2015), so male rats were used for the present experiments. After arrival, rats were given 1 week to acclimate to the colony room before experimentation commenced. Food (Laboratory Rodent Diet 5001; LabDiet) and water were available ad libitum until the onset of cocaine self-administration. Starting $2 \mathrm{~d}$ before the first day of self-administration, access to food was controlled $(\sim 20-24 \mathrm{~g}$ of regular chow per day) to maintain a stable body weight throughout testing, and to prevent the unhealthy obesity associated with long-term ad libitum feeding in male rats (Rowland, 2007). All procedures were approved by the University of Michigan Institutional Animal Care and Use Committee and were conducted in laboratories accredited by the Association for Assessment and Accreditation of Laboratory Animal Care.

\section{Phenotyping GTs and STs}

Apparatus. Med Associates test chambers $(20.5 \mathrm{~cm} \times 24.1 \mathrm{~cm}$ floor area, $29.2 \mathrm{~cm}$ high) were used for Pavlovian conditioned approach (PCA) training (Meyer et al., 2012; Pitchers et al., 2017). Each chamber was equipped with a food receptacle located $2.5 \mathrm{~cm}$ above the floor in the center of the wall. A catch tray filled with corncob bedding was located underneath the floor, which was constructed from stainless steel rods. A red house light was located on the wall opposite the food receptacle and remained on for the duration of training sessions. A retractable lever (Med Associates) was located $\sim 2.5 \mathrm{~cm}$ to the left or right of the food receptacle $6 \mathrm{~cm}$ above the floor. The side of the lever with respect to the food receptacle was counterbalanced across boxes. A white LED was located inside the lever housing and was used to illuminate the slot through which the lever protruded when it was extended. The lever required an $\sim 15 \mathrm{~g}$ force to deflect, such that most contacts with the lever were recorded as a "lever press." The pellet dispenser (Med Associates) delivered one $45 \mathrm{mg}$ banana-flavored food pellet (\#F0059; Bio-Serv) into the food receptacle at a time. Head entry into the food receptacle was recorded each time a rat broke the infrared photobeam located inside the receptacle ( $\sim 1.5 \mathrm{~cm}$ above the base of the food cup). Each conditioning chamber was located in a sound-attenuating enclosure and background noise was supplied by a ventilating fan. Data collection was controlled by Med-PC software.

PCA training. During the initial 1 week acclimation period, rats were handled regularly. All training sessions were conducted during the $12 \mathrm{~h}$ lights-on period. Before the start of training, $\sim 20$ banana-flavored food pellets were placed into the rats' home cages to familiarize the animals with this food. For pretraining, rats were placed into the test chamber with a red house light illuminated and, while the lever remained retracted, 25 food pellets were delivered on a variable interval (30 s) schedule to ensure that rats reliably retrieved pellets from the receptacle.

During a PCA training session, each individual trial consisted of the insertion of the illuminated lever (CS) into the chamber for $8 \mathrm{~s}$ and, immediately after the retraction of the lever, the activation of the pellet dispenser caused the delivery of a single food pellet (unconditioned stimulus, US) into the food receptacle. The intertrial interval (ITI) started immediately after retraction of the lever. The CS was presented on a variable interval $90 \mathrm{~s}$ schedule such that one presentation of the CS occurred on average every $90 \mathrm{~s}$, but the actual time between CS presentations varied randomly between 30 and $150 \mathrm{~s}$. Each Pavlovian training session consisted of 25 trials yielding 35-40 min sessions. PCA training was conducted over 5 consecutive days. For each trial, the following measures were taken: (1) number of lever deflections (contacts), (2) latency to first lever deflection, (3) number of head entries into the food cup (referred to as food cup entries) during presentation of the CS, (4) latency to the first cup entry after CS presentation, and (5) number of cup entries during the ITI. All animals included in the final analysis consumed all food pellets during each training session. 
At the conclusion of PCA training, the propensity of each individual rat to approach the lever CS versus the food cup during the CS period (i.e., ST or GT conditioned response, CR) was calculated using a PCA index score, as described previously (Meyer et al., 2012). Briefly, the PCA index score consisted of averaging three measures of conditioned approach: (1) the probability of contacting either the lever CS or food cup during the CS period $\left(P_{\text {(lever) }}-P_{\text {(food cup })}\right)$; (2) the response bias for contacting the lever CS or the food cup during the CS period: (\#lever CS contacts - \#food up contacts)/(\#lever CS contacts + \#food cup contacts); and (3) the latency to contact the lever CS or the food cup during the CS period: (food cup contact latency - lever CS contact latency)/8. Averaging these three measures produces PCA index scores along a scale ranging from -1.0 to +1.0 , where +1 indicates an animal made a signtracking CR on every trial and -1 a goal-tracking CR on every trial and 0 a 50:50 distribution of sign- and goal-tracking CRs. For the purpose of classification, rats with an averaged PCA index score from days 4 and 5 ranging from -1.0 to -0.5 were operationally defined as GTs (i.e., rats more likely to direct behavior toward food cup than lever) and rats with a PCA index score between +0.5 and +1.0 were designated as STs (i.e., rats more likely to direct behavior toward the lever CS than food cup). Of the rats screened for PCA behavior, 19 STs and 17 GTs were used in the experiment described below.

\section{Intravenous catheter surgery}

After PCA training, chronic indwelling catheters were implanted into the right jugular vein of all rats, as described previously (Crombag et al., 2000). Briefly, animals were anesthetized initially with $5 \%$ isoflurane in an anesthetic chamber (Anesco/Surgivet) then maintained with 2\% isoflurance via nose cone. Gas was carried via oxygen at a flow rate of 0.6 $\mathrm{L} / \mathrm{min}$. Animals' body temperatures were maintained at $37^{\circ} \mathrm{C}$ using Deltaphase isothermal pads (Braintree Scientific) and ophthalmic ointment was provided for lubrication of the eyes. Postoperative pain was managed with carprofen $(5 \mathrm{mg} / \mathrm{kg}$, s.c.). The catheter exited through the dorsal skin surface between scapulae. After surgery, catheters were flushed daily with $0.2 \mathrm{ml}$ of sterile saline containing $5 \mathrm{mg} / \mathrm{ml}$ gentamicin sulfate (Vedco) to prevent occlusions and minimize infections. Catheter patency was tested periodically by intravenous injection of $0.15 \mathrm{ml}$ of methohexital sodium (10 mg/ml in sterile water; JHP Pharmaceuticals). Animals were removed from the experiment if they failed to become ataxic after infusion.

\section{Cocaine self-administration}

Apparatus. Cocaine self-administration, extinction, and reinstatement testing was conducted in behavioral chambers identical to those used for PCA training but equipped with different manipulanda and programmable features. The food cup and lever were removed from the chamber and replaced with 2 nose ports located $3 \mathrm{~cm}$ above the floor on the left and right sides of the wall opposite the red house light. The side of the nose port deemed "active" was counterbalanced between rats. Two identical LED stimulus lights (Med Associates) were placed on the front and back walls. The front cue light was located centrally between the 2 nose poke ports but $8 \mathrm{~cm}$ above the floor. The location of the back cue light mirrored the front cue light, but below the red house light. A syringe pump located outside of the sound attenuating chamber and connected to the rats' catheter back ports delivered cocaine infusions. The infusion tubing was suspended into the chamber via a swivel mechanism, which allowed free movement in the chamber.

Acquisition of cocaine self-administration. After implantation of chronic indwelling catheters and a recovery period $(\sim 7 \mathrm{~d})$, rats were trained to make an instrumental response (nose poke into the active nose port) to receive an intravenous injection of cocaine hydrochloride over $2.8 \mathrm{~s}(0.4$ $\mathrm{mg} / \mathrm{kg} /$ infusion, weight of the salt, dissolved in sterile saline $(0.9 \%)$; National Institute on Drug Abuse) on a fixed ratio (FR) 1 schedule of reinforcement, with $20 \mathrm{~s}$ timeout after each infusion. Responses into the active nose poke port during the timeout or into the inactive port at any time had no programmed consequence but were recorded. Importantly, no explicit experimenter-provided cue (CS) was associated with drug infusion during self-administration sessions. Rather than restricting the length of session, rats were required to earn a fixed number of infusions during each session (infusion criteria, IC), which increased across days (IC10, IC20, IC40). Session length was determined by number of infusions to ensure that all rats received the same amount of drug during self-administration training. Animals had three sessions at IC10 and IC20 and then five sessions at IC40.

Intermittent access cocaine self-administration. After acquisition of cocaine self-administration, rats were moved onto an IntA selfadministration schedule shown previously to generate high levels of motivation for cocaine (Zimmer et al., 2012). Rats were placed into the behavioral chamber with the red house light illuminated for $2 \mathrm{~min}$ before the beginning of the first 5 min drug available period, signaled by the illumination of the cue light located on the front wall. This cue light thus served as a discriminative stimulus signaling drug availability $\left(\mathrm{DS}^{+}\right)$. When the $\mathrm{DS}^{+}$was present, a response into the active port caused the administration of a single infusion of cocaine $(0.4 \mathrm{mg} / \mathrm{kg} /$ infusion over $2.8 \mathrm{~s}$ ) on a FR1 schedule and, again, no experimenter-provided cue was paired with drug delivery. Apart from this $2.8 \mathrm{~s}$ infusion interval during which the pump was on, no timeout was imposed to limit the number or timing of infusions within a drug available (DS ${ }^{+}$) period. After the $5 \mathrm{~min}$ drug available period, the $\mathrm{DS}^{+}$was turned off and the cue light on the back wall was turned on. This cue light served as a discriminative stimulus indicating drug unavailability (DS ${ }^{-}$). During the 25 min no-drug available $\left(\mathrm{DS}^{-}\right.$) period, nose pokes were recorded for each port, but responses in neither had any consequence. After $25 \mathrm{~min}$, the $\mathrm{DS}^{-}$was turned off and $\mathrm{DS}^{+}$was turned on again to signal another 5 min drug available period. Each IntA self-administration session consisted of 8 drug available $\left(\mathrm{DS}^{+}\right)$and 8 no drug available $\left(\mathrm{DS}^{-}\right)$periods, resulting in a $4 \mathrm{~h}$ session. This self-administration procedure results in a series of spiking brain cocaine concentrations, rapidly rising and returning back to baseline before the next drug available period (for the pharmacokinetic profile produced by this method, see Fig. 1 in Zimmer et al., 2012 and Fig. 2 in Allain et al., 2017). Each rat underwent IntA cocaine selfadministration for 14 consecutive daily sessions.

\section{Extinction (before surgery)}

After the last IntA self-administration session, rats underwent 7 daily $1 \mathrm{~h}$ sessions of extinction training. Under extinction conditions, responses into either nose port had no scheduled consequence (no drug) and neither the $\mathrm{DS}^{+}$nor DS ${ }^{-}$was illuminated. After completion of initial extinction training, all animals underwent surgery to lesion basal forebrain cholinergic neurons or sham surgery.

\section{Infusions of $192 \operatorname{IgG-saporin}$}

Animals were anesthetized initially with 5\% isoflurane in an anesthetic chamber (Anesco/Surgivet) then maintained with $2 \%$ isoflurance via nose cone. Gas was carried via oxygen at a flow rate of $0.6 \mathrm{~L} / \mathrm{min}$. The animals were mounted into a stereotaxic instrument (David Kopf Instruments). Animals' body temperatures were maintained at $37^{\circ} \mathrm{C}$ using Deltaphase isothermal pads (Braintree Scientific) and ophthalmic ointment was provided for lubrication of the eyes. Postoperative pain was managed with carprofen $(5 \mathrm{mg} / \mathrm{kg}$, s.c.). Infusions were made using a 30-gauge needle attached to a $1 \mu \mathrm{l}$ Hamilton syringe mounted on a stereotaxic arm. The cholinotoxic immunotoxin 192 IgG-saporin (SAP; Advanced Targeting System) was suspended in aCSF. Each rat received bilateral bolus infusions of the toxin $(200 \mathrm{ng} / \mu \mathrm{l} ; 0.5 \mu \mathrm{l} /$ hemisphere $)$ or aCSF into the basal forebrain, targeting the nucleus basalis of Meynert (nbM), substantia innominata (SI), magnocellular preoptic area (MCPO), and the horizontal diagonal band (HDB) (relative to bregma: AP: $0.8 \mathrm{~mm}$; ML: \pm 2.9 $\mathrm{mm}$; DV: $-6.8 \mathrm{~mm}$ from skull). The needle was left in position for $5 \mathrm{~min}$ after infusion to foster absorption of the toxin. Surgical clips were used to close the incision (removed $7 \mathrm{~d}$ later) and a topical antibiotic (Neosporin) was applied to the wound. This procedure yielded four experimental groups: ST sham $(n=10)$, ST SAP $(n=9)$, GT sham $(n=$ $9)$, and GT SAP $(n=8)$.

\section{Re-extinction and reinstatement}

Because spontaneous recovery of drug seeking can occur after a period of abstinence (Shaham et al., 1997), 3 weeks after lesion surgery, animals underwent 5 additional extinction sessions (re-extinction) using extinction training conditions that were identical to those used presurgery. This 
extinction training was followed on the next day by a single $1 \mathrm{~h}$ test for $\mathrm{DS}^{+}$-induced reinstatement of drug-seeking behavior. During this session, the $\mathrm{DS}^{+}$was repeatedly presented noncontingently for $2 \mathrm{~s}$ with a variable ITI of 15-45 s. The rats' responses were recorded but had no programmed consequence. Reinstatement was assessed by an increase in responding during the session in which the $\mathrm{DS}^{+}$was presented relative to that on the last day of extinction; we were primarily interested in whether this differed between STs and GTs.

In addition to the automated measures of behavior, the rats were recorded using a digital video recording system and videos were subsequently scored offline. For technical reasons, videos were available only for a subset of rats/sessions (ST sham, $n=5$; ST SAP, $n=5$; GT sham, $n=3$; GT SAP, $n=6$ ). An orienting response was scored if the rat made a head and/or body movement in the direction of the DS when it was presented regardless of whether the rat approached the DS. We also recorded when active responses were made relative to $\mathrm{DS}^{+}$presentations (during a period of $4 \mathrm{~s}$ after DS ${ }^{+}$and during a $26 \mathrm{~s}$ period while the DS ${ }^{+}$ was not present). Furthermore, we recorded whether an active response was made during or immediately after an orientation response to the DS ${ }^{+}$.

\section{Histological analyses}

At the conclusion of the experiment, animals were deeply anesthetized using sodium pentobarbital $(270 \mathrm{mg} / \mathrm{kg}$, i.p.) and perfused intracardially with $50 \mathrm{ml}$ of $0.9 \%$ saline, followed by $500 \mathrm{ml}$ of $4 \%$ paraformaldehyde in $0.1 \mathrm{M}$ phosphate buffer (PB). Brains were removed and postfixed for $1 \mathrm{~h}$ at $4^{\circ} \mathrm{C}$ in the same fixative and then immersed in $20 \%$ sucrose and $0.01 \%$ sodium azide in $0.1 \mathrm{M} \mathrm{PB}$ and stored at $4^{\circ} \mathrm{C}$. Coronal sections $(40 \mu \mathrm{m})$ were cut with a freezing microtome (SM 2000R; Leica), collected in four parallel series in cryoprotectant solution (30\% sucrose and 30\% ethylene glycol in $0.1 \mathrm{M} \mathrm{PB}$ ), and stored at $-20^{\circ} \mathrm{C}$ until additional processing.

Sections of all animals were used to verify the extent of the lesion. Free-floating sections were washed extensively with $0.1 \mathrm{M}$ PBS, pH 7.37.4, between incubations. Sections were exposed to $1 \% \mathrm{H}_{2} \mathrm{O}_{2}$ for $10 \mathrm{~min}$ at room temperature (RT) to destroy endogenous peroxidases then blocked in PBS+ incubation solution, which was PBS containing $0.1 \%$ bovine serum albumin (Jackson ImmunoResearch Laboratories) and $0.4 \%$ Triton X-100 (Sigma-Aldrich) for $1 \mathrm{~h}$. After blocking in PBS+, sections were incubated overnight at RT in a goat anti-ChAT polyclonal antibody (1:500 in PBS+; Millipore). Sections were then incubated for $1 \mathrm{~h}$ in biotin-conjugated rabbit anti-goat IgG (1:500 in PBS+; Vector Laboratories) and then for $1 \mathrm{~h}$ in avidin-biotin-horseradish peroxidase (ABC elite; 1:1000 in PBS; Vector Laboratories). After ABC incubation, the peroxidase complex was visualized after treatment to a chromogen solution containing $0.02 \% 3,3^{\prime}$-diaminobenzidine tetrahydrochloride (DAB; Sigma-Aldrich) in $0.1 \mathrm{M}$ PB with hydrogen peroxide $(0.015 \%)$ for $10 \mathrm{~min}$. Sections were washed thoroughly in $0.1 \mathrm{M} \mathrm{PB}$ to terminate the reaction and mounted onto coded Superfrost plus glass slides (Fisher Scientific) with $0.3 \%$ gelatin in $\mathrm{dd}_{2} \mathrm{O}$. After dehydration, all slides were coverslipped with DPX mounting medium (dibutyl phthalate xylene; Electron Microscopy Sciences).

To verify the placement and degree of cholinergic losses, a semiquantitative estimate of the number of residual cholinergic neurons, as indicated by number of choline acetyltransferase-immunoreactive (ChAT-IR) neurons, was generated. An average of 10 sections per brain was examined, with the range of levels extending from $-0.2 \mathrm{~mm}$ relative to bregma to -1.5 $\mathrm{mm}$ relative to bregma. In addition, the basal forebrain of each section was divided into two major subregions consisting of the nbM and the ventral basal forebrain (vbf) plus MCPO and HDB (Paxinos and Watson, 2007). Images of each of the sections were taken at $10 \times$ using a Leica DM400B digital microscope. Cell counts for the nbM were included within a $1400 \times 1600 \mu \mathrm{m}$ area and for the vbf within a $800 \mu \mathrm{m} \times 2150$ $\mu \mathrm{m}$ region. ChAT-IR cells were also counted in the vertical limb of the diagonal band (within a $150 \times 300 \mu \mathrm{m}$ ) region to determine whether the toxin also affected cholinergic projections to the hippocampus. Cell counts from both hemispheres were averaged. Sections were grouped by their AP position relative to bregma in the following ranges: $-0.2 \mathrm{~mm}$ to $-0.5 \mathrm{~mm},-0.6 \mathrm{~mm}$ to $-0.9 \mathrm{~mm},-1.0 \mathrm{~mm}$ to $-1.2 \mathrm{~mm}$ and -1.3 to $-1.5 \mathrm{~mm}$. Cell counts from images within a given range were averaged to produce a single estimate of residual cell numbers per range. The

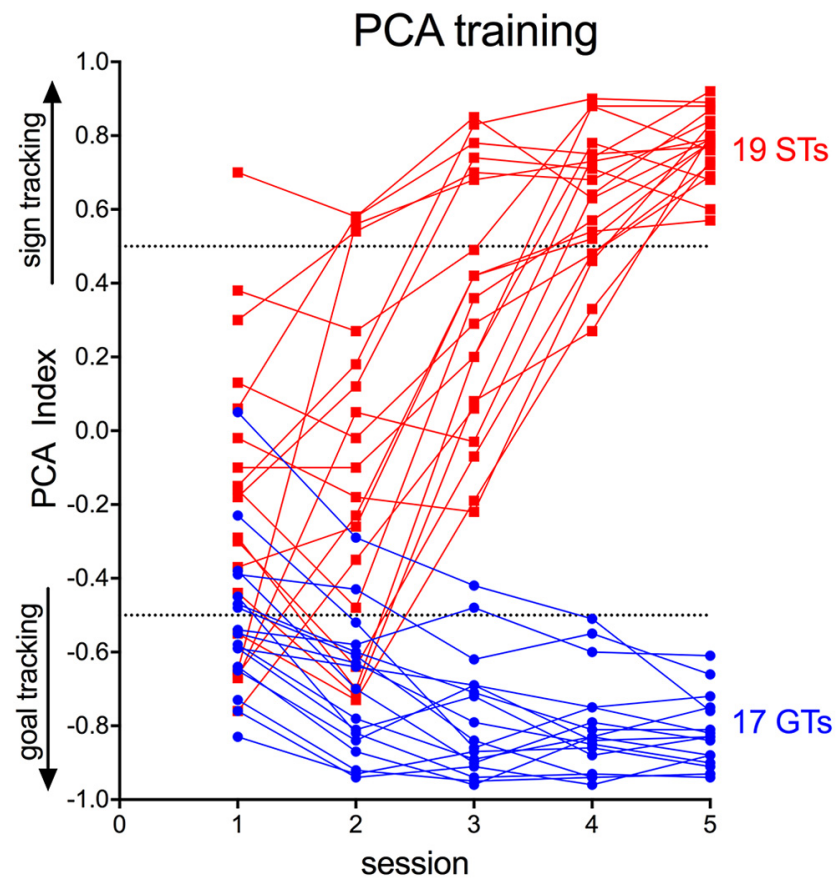

Figure 1. Individual PCA index values across the five PCA training sessions for STs and GTs (data from rats eventually classified as intermediates are not shown). The final classification of the ST or GT phenotype ( $n=19$ and 17, respectively) was based on averaging PCA index values from PCA sessions 4 and 5 . The predetermined PCA index score cutoffs for STs and GTs were 0.5 and -0.5 , respectively.

point tool on ImageJ was used to count each ChAT-IR neuron in each image. Two individuals blind to the experimental groups counted all ChAT-positive cells and the cell counts of the two counters were averaged.

\section{Experimental design and statistical analysis}

The present experiments were designed to test the following explicit hypotheses: (1) that a $\mathrm{DS}^{+}$would evoke drug-seeking behavior to a greater extent in GTs than STs and (2) that $\mathrm{DS}^{+}$-evoked drug-seeking behavior in GTs, but not STs, would be attenuated by forebrain cholinergic depletion. Therefore, experimental groups consisted of STs and GTs that were selected from outbred rats using an established PCA test and criteria for categorization of the phenotypes. Furthermore, STs and GTs were randomly assigned to receive either infusions of the cholinotoxin or vehicle into the basal forebrain. As indicated in the "Animals" section, there are not marked sex differences in the expression of the ST/GT phenotype is not affected by sex (Pitchers et al., 2015) and thus experiments were conducted using male rats. Final group sizes were $n=$ 17 GTs ( 9 sham, 8 SAP) and $n=19$ STs ( 10 sham, 9 SAP).

The primary results from this study concern the number of responses to the active port in sham-operated and lesioned STs and GTs (see Fig. 6). ANOVA was used to analyze active/inactive responses made during the $\mathrm{DS}^{+}$reinstatement test. Linear mixed-model (LMM) analysis was used for all repeated-measures data. The covariant structure was explored and modeled for each dependent variable. The best-fitting model of repeated measures covariance was determined by the lowest Akaike information criterion score (West et al., 2006). Significant main effects and interactions are indicated with uncorrected degrees of freedom to maintain the transparency of the experimental design (Sarter and Fritschy, 2008). When main effects were found, post hoc comparisons were made (Bonferroni test) and $\alpha$ was set at 0.05 . For the analysis of reinstatement behavior, effect sizes (Cohen's $d$ ) are also reported. In accordance with prior recommendations, exact $p$ values are reported whenever applicable (Greenwald et al., 1996). 

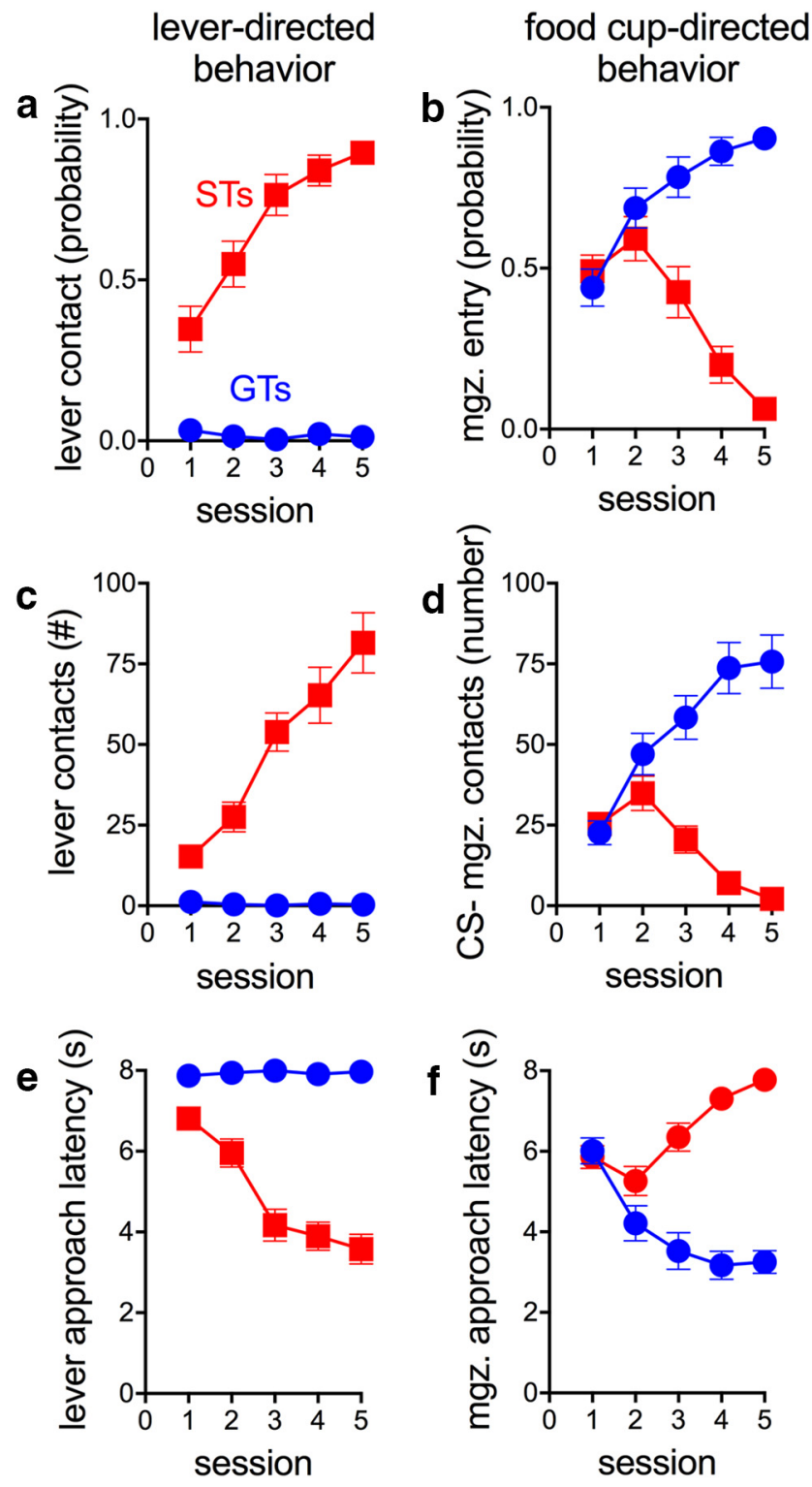

Figure 2. Measures of behavior toward a lever (CS; left column) versus the location of food delivery (food magazine or cup; right column) over the five PCA training sessions of rats that were eventually classified as STs $(n=19)$ or GTs $(n=17)$. The plots depict the mean \pm SEM for the probability of approaching the lever $C S$ during the $8 s$ CS period $(\boldsymbol{a})$, the probability of approaching the food cup during the $8 \mathrm{~s}(\mathrm{~S}$ period $(\boldsymbol{b})$, the number of lever contacts $(\boldsymbol{c})$, the number of food cup entries during the $8 \mathrm{~s}$ CS period $(\boldsymbol{d})$, latency to first lever contact after CS presentation $(\boldsymbol{e})$, and the latency to the first food cup entry after $\mathrm{CS}$ presentation $(\boldsymbol{f})$. STs increasingly and more rapidly contacted the $C S(a, c, e)$, whereas GTs increasingly contacted the site of reward delivery (mgz., magazine; $\boldsymbol{b}, \boldsymbol{d}, \boldsymbol{f}$ ).

\section{Results}

\section{PCA performance-based phenotyping}

Distinct phenotypes emerged as a result of PCA training, as reported previously (Flagel et al., 2009; Meyer et al., 2012). Rats classified as GTs based on average PCA scores from sessions 4 and 5 (Fig. 1) rarely approached the lever CS, but rather, over the 5 training sessions, learned to approach the food cup reliably and rapidly (Fig. $2 b, d, f$ ). Conversely, STs learned to approach and contact the lever preferentially and rapidly (Fig. $2 a, c, e$; note that Figs. 1 and 2 do not show data from intermediate rats). These food cup- or lever (CS)-directed behaviors increased across training days for GTs and STs, respectively (Figs. 1,2). The resulting

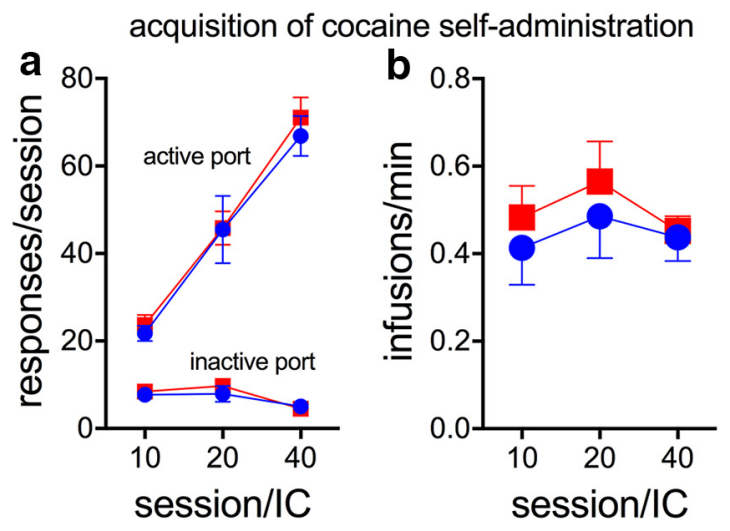

Figure 3. Acquisition of cocaine self-administration by STs (red; $n=19$ ) and GTs (blue; $n=$ 17) using an IC-based approach. Acquisition of self-administration did not differ between the phenotypes with respect to the number of responses ( $\boldsymbol{a}$ ) to the active (circles) or inactive (squares) ports and the number of cocaine infusion/min (b) for IC 10, IC20, or IC40 (0.4 mg/kg/ infusion; for results from LMM analyses, see Results).

STs $(n=19)$ and GTs $(n=17)$ had PCA index scores between +0.53 and +0.88 (mean \pm SEM: $+0.70 \pm 0.03$ ) and -0.60 to $-0.94(-0.82 \pm 0.03)$, respectively.

\section{Acquisition of cocaine self-administration}

After PCA training, rats were trained to self-administer cocaine using an infusion criterion-based procedure (Saunders and Robinson, 2010). Animals were required to self-administer a fixed number of drug infusions each session (IC10, IC20, or IC40). Therefore, any differences in the acquisition of cocaine selfadministration would be evident with respect to the number of nose pokes into the active versus inactive port or the rate of self-administrations (average number of cocaine infusions taken per minutes). Across phenotypes, the number of active and inactive responses significantly increased and decreased across training, respectively (active: $F_{(2,35)}=94.93, p<0.001$; inactive: $F_{(2,35)}$ $=6.96, p=0.003$; Fig. $3 a$ ), whereas infusion rate remained steady across training $\left(F_{(2,35)}=1.24, p=0.30\right.$; Fig. 3b). STs and GTs did not differ in the acquisition of cocaine self-administration behavior, as indicated by a similar number of nose pokes into the active $\left(F_{(1,35)}=0.02, p=0.63\right)$ and inactive ports $\left(F_{(1,35)}=0.20, p=\right.$ 0.66 ; Fig. $3 a)$ and by completing self-administration sessions within the same amount of time $\left(F_{(1,35)}=1.39, p=0.25\right.$; Fig. $3 b$; effects of phenotype $\times$ session on all measures: all $F<0.52$, all $p>0.60$ ). These results confirm previous findings that with this procedure STs and GTs do not differ in the acquisition of cocaine self-administration behavior (Saunders and Robinson, 2010; Pitchers et al., 2017).

\section{Int $A$ cocaine self-administration}

IntA cocaine self-administration training lasted for a total of 14 sessions. Both STs $(n=19)$ and GTs $(n=17)$ escalated total cocaine intake (number of infusions) between the first to 14th session $\left(F_{(13,35)}=6.07, p<0.001\right.$; Fig. $\left.4 a\right)$, consistent with previous reports (Kawa et al., 2016; Allain et al., 2017). STs selfadministered a significantly higher number of infusions compared with GTs over these 14 sessions (main effect of phenotype: $F_{(1,35)}=4.85$, $P=0.035$; phenotype $\times$ session: $F_{(13,35)}=1.49, P=0.18$; Fig. $4 a$ ), but the number of responses to active ports increased over sessions in both STs and GTs, indicating that both phenotypes acquired the discrimination at the same rate (main effect of session: $F_{(13,35)}=25.78, p<0.001$; no effect of phenotype: $F_{(1,35)}=$ 


\section{IntA cocaine self-administration}
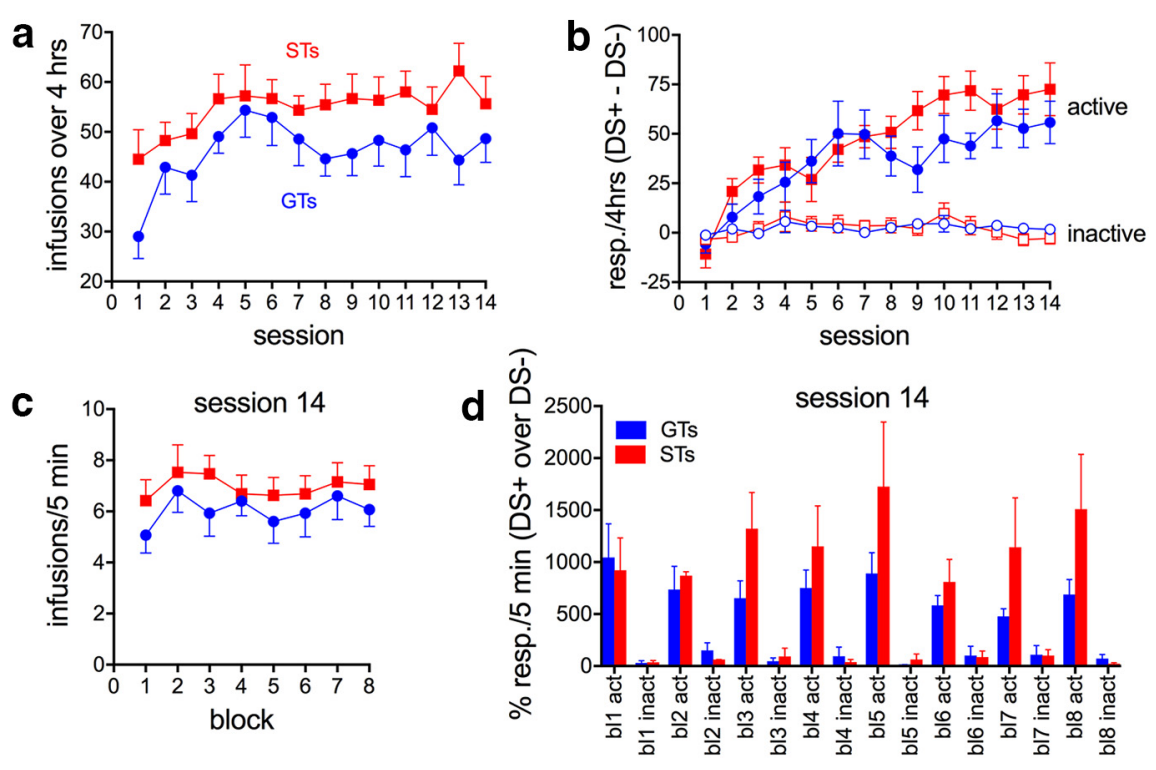

Figure 4. After animals learned to self-administer cocaine, they learned to self-administer cocaine in accordance with an IntA schedule. Both STs $(n=19)$ and GTs $(n=17)$ escalated cocaine intake over 14 IntA sessions, with STs having consumed a greater amount of cocaine across IntA training $(\boldsymbol{a})$. Over 14 sessions, the difference between responses to the active port in the presence of the DS ${ }^{+}$and the DS ${ }^{-}$(filled symbols in $\boldsymbol{b}$ ) increased at the same rate in STs and GTs. The difference between inactive responses in the presence of the $\mathrm{DS}^{+}$and the $D S^{-}$remained near zero over sessions (open symbols in $\boldsymbol{b}$; note that, for calculating these differences, the number of responses during the $25 \mathrm{~min} \mathrm{DS}^{-}$periods was divided by 5 to match the 5 min $\mathrm{DS}^{+}$periods). By the end of IntA training (session \#14), STs and GTs' cocaine consumption did not differ (c). $\boldsymbol{d}$ shows, for each block of session \#14, the percentage active and inactive responses for the $\mathrm{DS}^{+}$periods relative to the $\mathrm{DS}^{-}$periods (resp, responses; act, active, inact, inactive; mean \pm SEM). During DS ${ }^{+}$periods, responses to the active, but not inactive, port were $500-2000 \%$ over DS ${ }^{-}$periods, indicating that both STs and GTS effectively discriminated between the DS ${ }^{+}$(drug available) and DS ${ }^{-}$(no-drug available) periods (note that, for the calculation of the data in $\boldsymbol{d} \mathrm{DS}^{-}$responses of zero were replaced by one).
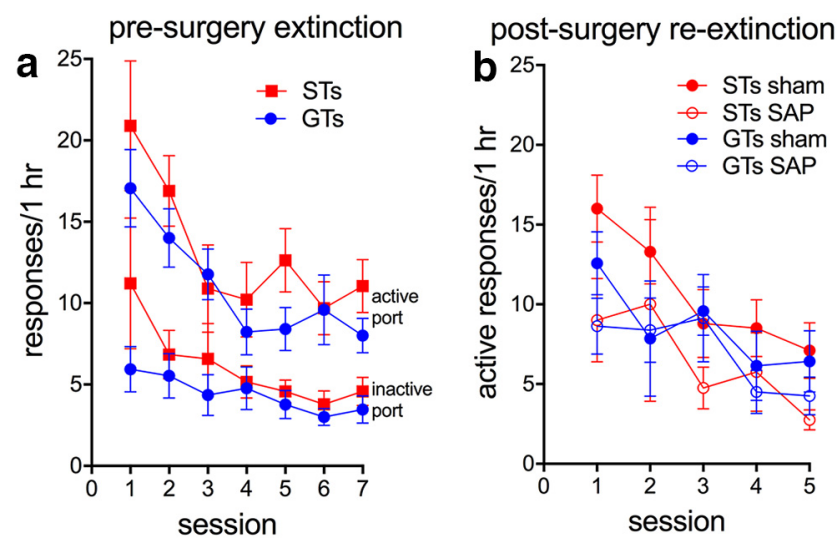

Figure 5. a, Initial extinction of drug-seeking behavior (no DS ${ }^{+}$, no cocaine) caused a decrease in the number of responses to the active and inactive nose port in both STs $(n=19)$ and GTs $(n=17)$. $\boldsymbol{b}$, Three weeks after surgery (ST sham, $n=9$; ST SAP, $n=10$; GT sham, $n=9$; GTSAP, $n=8$ ), re-extinction again decreased the number of active responses in all groups (for LMM analyses, see Results).

$1.33, P=0.25$; phenotype $\times$ session: $F_{(13,35)}=1.61, P=0.10$; Fig. $4 b)$. At the same time, inactive responses did not differ between the presence of the $\mathrm{DS}^{+}$and the $\mathrm{DS}^{-}$(open symbols in Fig. $4 b$; all $F<1.72$, all $p>0.5$ ).

By the final IntA session (\#14), the number of infusions did not differ between STs and GTs $\left(F_{(1,35)}=1.23, p=0.28\right)$ and did not vary by block ( 1 block consisted of a 5 min period of $\mathrm{DS}^{+}$/ drug availability and a $25 \mathrm{~min}$ period of $\mathrm{DS}^{-} /$no drug availability; $F_{(7,35)}=1.30, p=0.27$; Fig. $\left.4 c\right)$. Importantly, by the final session 0.56; Fig. $5 a)$.
(\#14), STs and GTs did not differ in the number of active responses made throughout the session $\left(F_{(1,35)}=2.00, p=\right.$ $0.17)$ and response rates indicated that both STs and GTs discriminated between drug available (DS ${ }^{+}$) and drug not available (DS ${ }^{-}$) periods (main effect of stimulus condition: $F_{(1,35)}=51.89, p<0.001$; phenotype $\times$ stimulus condition: $\mathrm{F}_{(1,35)}=$ $0.69, p=0.41$; Fig. $4 d$; for this analysis, the number of responses during the $25 \mathrm{~min}$ $\mathrm{DS}^{-}$periods was divided by 5 to match the 5 min $\mathrm{DS}^{+}$periods). During this last IntA session, the number of responses to the inactive port was generally low and did not differ by phenotype or stimulus condition (main effects and interaction; all $F<1.36$, all $p>0.25$; mean \pm SEM: $0.46 \pm 0.10$ inactive responses $/ 5 \mathrm{~min}$ ).

\section{Extinction of drug-seeking behavior}

The goal of extinction training was to reduce greatly the number of responses to the active as well as inactive nose ports so that the subsequent test of the effects of $\mathrm{DS}^{+}$presentation were not confounded by persistent, phenotype-specific differences in response rates. Upon completion of all cocaine IntA self-administration training, rats underwent extinction training (seven sessions) during which an active response no longer resulted in a cocaine infusion. Extinction sessions were also void of any $\mathrm{DS}^{+} / \mathrm{DS}^{-}$presentations. The initial extinction training was conducted before surgery and successfully attenuated drug-seeking behavior in both phenotypes (main effect of session; active responses: $F_{(6,35)}=5.23, p<0.001$; inactive responses: $F_{(6,35)}=3.73, p=0.006$; main effect of phenotype; active responses: $F_{(1,35)}=1.10, p=0.300$; inactive responses: $F_{(1,35)}=$ $1.14, p=0.29$; session $\times$ phenotype: both $F<0.82$, both $p>$

After surgery, additional extinction training (re-extinction) was conducted to counter any spontaneous recovery of drug seeking during the 3-week postsurgery recovery period. Re-extinction training occurred over $5 \mathrm{~d}$ and was found again to decrease drug-seeking behavior (main effect of session on responses to active port: $F_{(4,35)}=$ $8.15, p<0.001)$. This effect was neither modulated phenotype or lesion (both $F<2.95$, both $p>0.1$ ) nor did the effects of session, phenotype, and lesion interact significantly $\left(F_{(4,35)}=1.20, p=\right.$ $0.32)$. The number of inactive responses likewise decreased over sessions $\left(F_{(4,35)}=11.10, p<0.001\right)$, but there were no other main effects or interactions (all $F<0.66$, all $p>0.62$ ).

\section{Reinstatement of drug-seeking behavior by presentation of the DS ${ }^{+}$}

After extinction, rats were tested for the ability of the $\mathrm{DS}^{+}$to reinstate drug-seeking behavior above that during the last extinction session. During a $1 \mathrm{~h}$ test session, the $\mathrm{DS}^{+}$was presented for $2 \mathrm{~s}$ and successive presentations were separated by an ITI of $15-45 \mathrm{~s}$. Figure $6 a$ shows that presentation of the $\mathrm{DS}^{+}$produced a greater reinstatement of drug-seeking behavior (more active responses) in sham-operated GTs than sham-operated STs and that the loss of cholinergic neurons reduced drug seeking behav- 
ior in GTs but not STs (phenotype $\times$ lesion: $F_{(1,35)}=4.75, p=0.037$; main effect of phenotype: $F_{(1,35)}=3.46, p=0.07$; lesion: $F_{(1,35)}=2.68, p=0.11$; for results of multiple comparisons on the interaction, see Fig. $6 a$ ). The difference between active responses by sham-operated GTs versus sham-operated STs, as well as the reduction of active responses as a result of cholinergic losses in GTs, were relatively large as indicated by Cohen's $d=1.35$ and $d=$ 1.18 , respectively.

Additional post hoc analyses of the active response rates in the presence of the $\mathrm{DS}^{+}$focused on the question of whether response rates were bound to the $\mathrm{DS}^{+}$or if the $\mathrm{DS}^{+}$perhaps generated a more persistent motivational state, thus increasing active responses throughout the session. We therefore analyzed active response rates separately for a $4 \mathrm{~s}$ period that began with the onset of the $\mathrm{DS}^{+}$and for the 15-45 s (average: $26 \mathrm{~s}$ ) periods thereafter (non-DS ${ }^{+}$; based on a subset of videotaped rats; see Materials and Methods). There was a trend for active response rates during the $4 \mathrm{~s}$ post-DS ${ }^{+}$periods to reproduce the analyses of response rates for the entire session, but effects of phenotype and lesion did not reach significance (all $F$ $<2.27$, all $p>0.15$; Fig. $6 b$ ). In contrast, response rates during non-DS ${ }^{+}$periods again were significantly higher in shamoperated GTs compared with shamoperated STs (phenotype $\times$ lesion: $F_{(1,18)}$ $=5.13, p=0.039$; main effects: both $F<$ 1.93, both $p>0.19$; Fig. $6 c$ ). Therefore, higher active response rates evoked by the $\mathrm{DS}^{+}$in sham-operated GTs extended to the entire session.

\section{Conditioned orientating behavior}

The evidence that the $\mathrm{DS}^{+}$acquired motivational properties during IntA selfadministration is that its noncontingent presentation renewed drug-seeking behavior after extinction (Fig. 6a). One reason that the basal forebrain cholinergic losses may have decreased the ability of the $\mathrm{DS}^{+}$to evoke drug-seeking behavior is because it degraded the motivational value of the DS ${ }^{+}$. However, other possibilities are that the lesion impaired the memory of the association between the $\mathrm{DS}^{+}$and drug availability (or retrieval of this memory) or the ability to perceive the stimulus. It is difficult to dissociate these alternative explanations, but we attempted to do so by looking at another conditioned response often seen in response to a localizable CS: conditioned orienting behavior (Saunders and Robinson, 2012; Yager and Robinson, 2013; Yager et al., 2015).

During the reinstatement test, all groups oriented similarly to the $\mathrm{DS}^{+}$and there were no group differences in conditioned orienting behavior (no effect of phenotype, cholinergic losses, or interaction between these two and all three factors; all $F<0.747$, all $p>0.40$; Fig. $6 d$ ). Although not definitive, these data support Results). reinstatement of cocaine seeking
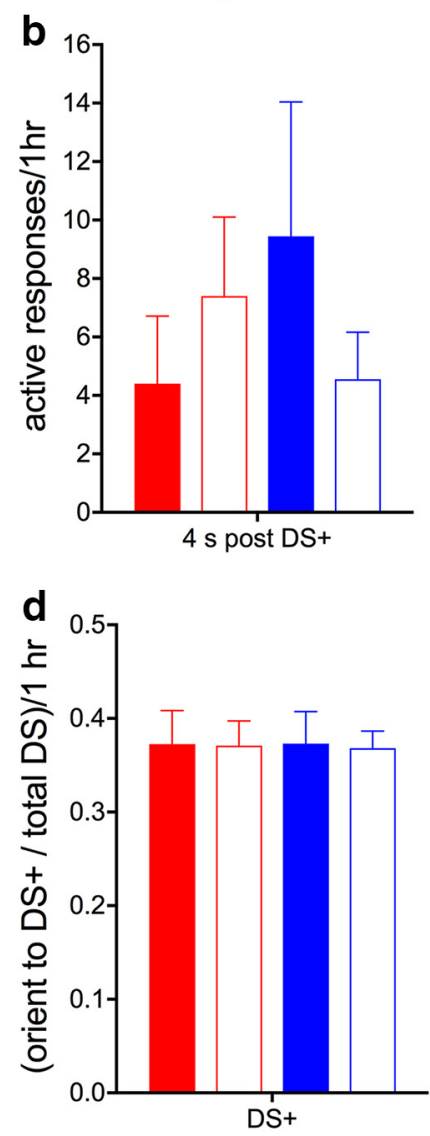

Figure 6. Number of responses to the active response port in the presence of the DS ${ }^{+}$by sham-operated GTs $(n=9)$ and STs $n=5$. ST SAP, $n=5 \cdot$ GT sham $n=3 \cdot$ GT SAP $n=6$ ) further indicated that the relatively high levels of DS ${ }^{+}$-evoked active responses in sham-operated GTs observed throughout the session (a) occurred, although insignificantly, during the 4 s period after the onset of the $D S^{+}(\boldsymbol{b})$ and, significantly, during the 26 s periods outside the presence of the DS ${ }^{+}(\boldsymbol{c})$. There were no significant effects of phenotype, SAP lesion, or of the interaction between the two factors on responses to the inactive port in either stimulus (see Results for ANOVA; data not shown). $\boldsymbol{d}$, Number of orientation responses toward the DS ${ }^{+}$relative to the total ientation rates to the DS ${ }^{+}$. Compared with GTs with cholinergic losses and sham-operated STs, sham-operated GTs were $>3$ times more likely to exhibit a response to the active nose port if they exhibited an orientation response in that trial (see

the interpretation that, after the basal forebrain lesion, all groups could still perceive the $\mathrm{DS}^{+}$and the $\mathrm{DS}^{+}$maintained "informational value" in all rats.

The results described above also indicate incomplete relationships between orienting and generating a response to the active nose port. Therefore, we also determined the probability that an active response was made given that rats exhibited an orienting response to the $\mathrm{DS}^{+}$. Compared with sham-operated GTs, GTs with cholinergic losses were more than $\sim 3$ times less likely to generate an active response even if they oriented to the $\mathrm{DS}^{+}$(GT sham: $P_{\text {(active response I orienting response) }}=0.10 \pm 0.01$; GT SAP: $0.03 \pm$ $\left.0.01 ; t_{(6)}=3.35, p=0.015\right)$.

\section{Contacts with the $\mathrm{DS}^{+}$or its location}

During our video analysis of the rats' behavior during the DS ${ }^{+}$ reinstatement test, we also recorded the number of cue contacts (nose within $\sim 1 \mathrm{~cm}$ ) during both $\mathrm{DS}^{+} \mathrm{ON}(2 \mathrm{~s})$ and $\mathrm{DS}^{+} \mathrm{OFF}$ 
sham
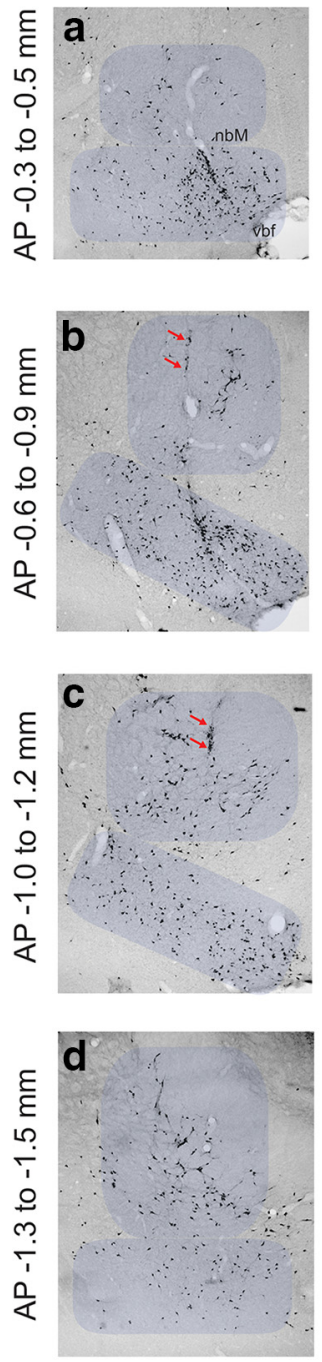
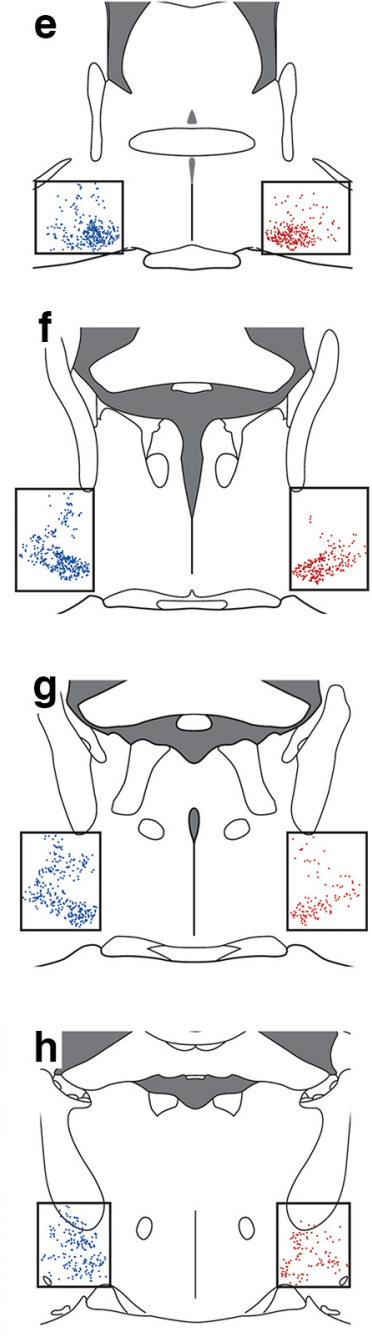

SAP
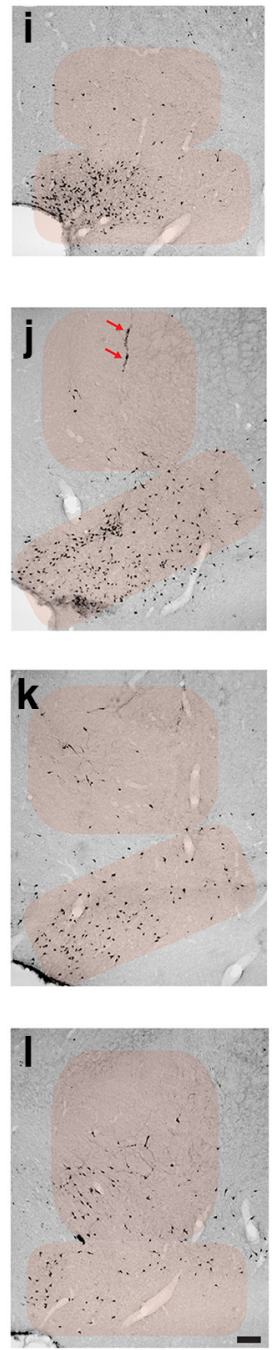

Figure 7. ChAT-IR neurons on coronal sections from sham-operated $(\boldsymbol{a}-\boldsymbol{d})$ and SAP-lesioned $(\boldsymbol{i}-\boldsymbol{I})$ rats at AP levels -0.4 , $-0.9,-1.1$, and -1.4 relative to bregma. Red arrows in $\boldsymbol{b}, \boldsymbol{j}$, and $\boldsymbol{c}$ indicate tracts produced by insertion of the infusion needle. The number of ChAT-IR neurons was estimated in two subregions of the basal forebrain: nbM and vbf (consisting of SI, MCPO, and HDB). Schematic drawings from each corresponding AP (middle column; $\boldsymbol{e}-\boldsymbol{h}$ ) illustrate the representative distribution of ChAT-IR neurons (blue dots) for sham-operated and the pattern of remaining neurons after SAP lesions (red dots; scale for all photomicrographs, in the bottom right corner in l:200 $\mu \mathrm{m})$.

(average of $28 \mathrm{~s}$ ). There were no effects of phenotype or lesion and no interaction between the two factors on the number of cue contacts in the presence or absence of the $\mathrm{DS}^{+}$(all $F<2.19$; all $p>0.16 ; \mathrm{DS}^{+} \mathrm{ON}: 14.26 \pm 0.94$ contacts, mean $\pm \mathrm{SEM} ; \mathrm{DS}^{+}$ OFF: $16.55 \pm 1.63$ contacts). These findings do not support the possibility that STs reinstated less because they made more frequent contacts with the $\mathrm{DS}^{+}$or, in its absence, the location of the $\mathrm{DS}^{+}$.

\section{Estimates and distribution of cholinergic losses}

Semiquantitative estimates of ChAT-IR neurons in the two subregions of the basal forebrain (nbM, vbf) of sham-operated rats did not differ between phenotypes (both $F_{(1,18)}<0.90$, both $p>0.35$; Figs. 7,8$)$. The number of ChAT-IR neurons varied by AP level for counts taken from the nbM and vbf (both $F_{(3,18)}>$ 16.87, both $p<0.001$; Fig. $8 a, b)$, but phenotype and level did not interact for estimates of either subregion (both $F_{(3,18)}<0.40$, both $p>0.75$; Fig. 8).
Estimates of residual neurons in the nbM varied by AP level $\left(F_{(3,16)}=44.90\right.$, $p<0.001)$, but not by phenotype $\left(F_{(1,16)}=\right.$ $0.24, p=0.63$; Fig. $8 c$ ). Furthermore, residual neuronal number estimates in STs were lower at level 3, but not at other levels, as indicated by a significant interaction between the effects of phenotype and level $\left(F_{(3,16)}=8.88, p=0.001\right)$ and multiple comparisons. Estimates of residual neuronal numbers in the vbf were not affected significantly by phenotype AP level or an interaction between these factors (all $F<3.13$, all $p>0.053$; Fig. $8 d$ ). Estimates of residual neuron numbers in the nbM of lesioned GTs did not correlate with their number of active responses in the presence of the $\mathrm{DS}^{+}$during the reinstatement test (all $r^{2}<0.08$; all $p>0.50$ ). Finally, estimates of cholinergic neurons in the vertical limb of the diagonal band were not affected by phenotype or lesion (main effects and interactions: all $F<0.31$, all $p>$ 0.58 ), indicating that the cholinergic losses did not include projections to the hippocampus.

\section{Discussion}

Rats identified as STs or GTs were trained to self-administer cocaine using an IntA self-administration procedure (Zimmer et al., 2012; Kawa et al., 2016) that alternated periods of drug availability and unavailability, signaled by a $\mathrm{DS}^{+}$and $\mathrm{DS}^{-}$, respectively. After $14 \mathrm{~d}$ of IntA experience, STs and GTs self-administered similar amounts of cocaine and effectively and similarly discriminated between drug available and drug not available periods. After extinction training, half of the STs and GTs received an immunotoxic lesion that eliminated $40-50 \%$ of basal forebrain cholinergic neurons. After recovery, they received more extinction training and then were tested to determine the ability of noncontingent presentations of the $\mathrm{DS}^{+}$to reinstate drug-seeking behavior. It was found that: (1) the $\mathrm{DS}^{+}$was more effective in reinstating cocaine seeking in control GTs than STs, the former making over twice as many active responses than the latter; (2) cholinergic cell loss reduced cocaine seeking in GTs to the level of sham-operated STs, but had no effect on active responses in STs; (3) STs and GTs, regardless of lesion condition (sham or SAP), similarly oriented to the DS ${ }^{+}$ during reinstatement tests; and (4) the probability of an active response, even in trials in which rats oriented to the $\mathrm{DS}^{+}$, was significantly higher in sham-operated GTs compared with GTs with cholinergic losses or sham-operated STs.

\section{$\mathrm{DS}^{+}$generated high levels of motivation for cocaine in GTs}

A substantial number of studies have demonstrated that localizable food and drug CSs acquire greater control over motivated behavior in STs than GTs, presumably because STs attribute more incentive salience to such cues than GTs (Flagel et al., 2007; 

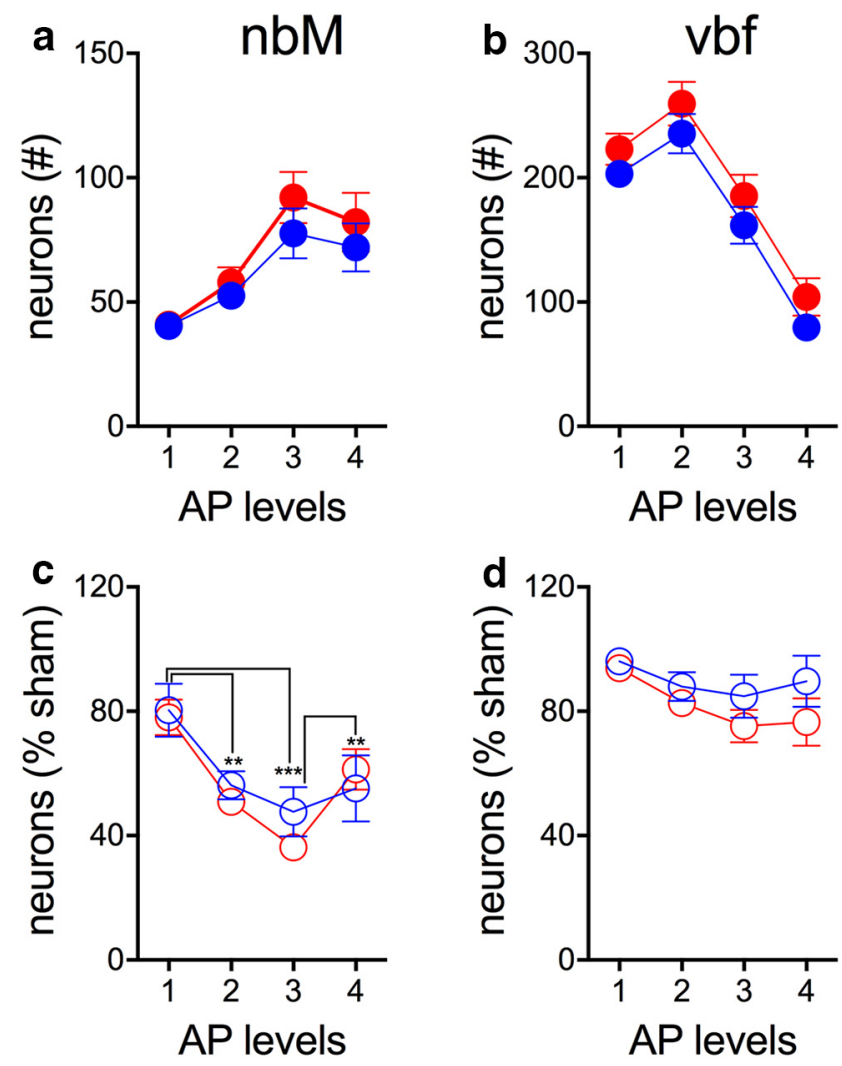

Figure 8. Semiquantitative estimates of ChAT-IR neurons in the two subregions of the basal forebrain (nbM, vbf; see also Fig. 7) of sham-operated STs (filled red circles; $\boldsymbol{a}$ ) and GTs (filled blue circles; $\boldsymbol{b}$ ) and after infusions of the cholinotoxin SAP (empty red and blue circles in c, nbM, and $\boldsymbol{d}$, vbf; ST sham: $n=10 ; \mathrm{GT}$ sham: $n=9 ;$ ST SAP: $n=9 ;$ GT SAP: $n=8$; AP levels: $1:-0.2$ to $-0.5 \mathrm{~mm}$ relative to bregma; 2 : -0.6 to $-0.9 \mathrm{~mm} ; 3:-1.0$ to $-1.2 \mathrm{~mm} ; 4:-1.3$ to -1.5 $\mathrm{mm}]$. Post hoc comparisons of main effects of AP level reflected in $\boldsymbol{a}$ that estimates at levels 1,2 , and 3 all differed from each other and in $\boldsymbol{b}$ that estimates at all levels differed from each other. For $\boldsymbol{c}$, the results of post hoc comparisons of effects of AP levels are indicated ( ${ }^{* *} p<0.01$, $\left.{ }^{* * *} p<0.001\right)$. A significant interaction between the effects of phenotype and AP levels on residual $n b M$ neuron number estimates $(\boldsymbol{c})$ reflected a lower number of residual cells at AP level $3(p=0.036)$ in STs compared with GTs.

Flagel et al., 2009; Saunders and Robinson, 2011; Yager and Robinson, 2013; Meyer et al., 2014; Yager et al., 2015; Singer et al., 2016; Flagel and Robinson, 2017) and because STs are more prone to bottom-up, stimulus-driven attention relative to GTs (Paolone et al., 2013; Koshy Cherian et al., 2017). However, the extent to which cues acquire motivational properties, and in which individuals, varies greatly as a function of the form of the cue (see Introduction). Given that DSs share many properties of contextual stimuli (see Introduction), we hypothesized that a $\mathrm{DS}^{+}$would reinstate cocaine seeking to a greater extent in GTs than STs, which it did.

$\mathrm{DS}^{+}$-evoked cocaine seeking was not tightly coupled to those periods of time when the $\mathrm{DS}^{+}$was present, but active responses were distributed throughout the test session, consistent with previous studies (Weiss et al., 2000). This finding is also similar to what was found in a prior experiment in which non-contingent presentation of a cocaine-paired cue (CS) evoked cocaine seeking behavior in the presence of an adverse consequence (Saunders et al., 2013). In that latter experiment, the cocaine cue was a CS paired temporally with each cocaine injection during selfadministration (not a DS) and this cue evoked greater reinstatement in STs than GTs, the opposite of here. There are multiple psychological/behavioral processes by which Pavlovian cues may promote relapse (Milton and Everitt, 2010). Saunders et al. (2013) suggested that, in their study, cue presentation may have generated a conditioned motivational "craving" state that lasted longer than the cue and this spurred drug-seeking actions (Bindra, 1968; Robinson and Berridge, 1993; Toates, 1998). Future research on the psychological processes mediating cocaine reinstatement in GTs will need to determine the DS ${ }^{+}$specificity of the present reinstatement procedure.

Here, the $\mathrm{DS}^{+}$may have also generated a conditioned motivational state, but the fact that the $\mathrm{DS}^{+}$produced greater drugseeking behavior in GTs than STs suggests that the proximate cause of such a state is presumably generated by different psychological processes in STs and GTs. Although speculative, discrete CSs more directly engage the bottom-up Pavlovian incentive motivational processes dominant in STs (Flagel et al., 2009; Meyer et al., 2012; Yager et al., 2015; Koshy Cherian et al., 2017). In contrast, presentation of a DS ${ }^{+}$signals drug availability and, given that GTs are more responsive to such shifts in context than STs, may have generated a more explicit cognitive expectation of drug in GTs. Such an expectation may then have secondarily heightened motivation or craving for drug via top-down control over dopaminergic motivational circuitry (Koshy Cherian et al., 2017). Indeed, in humans, craving is highest when there is an expectation that drug will soon be available (Dar et al., 2010). It may be that, in both cases, the neural systems responsible for the final conditioned motivational state that leads to drug-seeking behavior is the same, but the psychological and neurobiological processes by which that system is engaged could vary greatly depending on the individual and the form of the drug-associated cue. More research will be required to determine is this is true, but it is supported by the observation that renewed reward-seeking produced by both discrete CSs (ST > GT) and by a change in context (GT > ST) are DA dependent (Flagel et al., 2011; Saunders and Robinson, 2012; Saunders et al., 2014).

\section{Cue processing in STs and GTs and effects of cholinergic loss}

In GTs, but not STs, a neural system that appears to be necessary for $\mathrm{DS}^{+}$to generate motivation for cocaine involves cholinergic signaling because loss of basal forebrain cholinergic neurons markedly reduced $\mathrm{DS}^{+}$-evoked cocaine seeking in GTs, but had no effect in STs. The finding that both GTs and STs continued to show conditioned orienting behavior to the $\mathrm{DS}^{+}$to the same extent suggests that the $\mathrm{DS}^{+}$retained informational value in both phenotypes. Therefore, these data suggest that cholinergic losses did not interfere with the ability of GTs to perceive the stimulus nor their ability to remember its association with drug availability.

It has been shown that STs exhibit relatively low levels of attentional control, as indicated, for example, by fluctuating and relatively low levels of attentional performance (Paolone et al., 2013), and the propensity for impulsive action (Lovic et al., 2011). Associated with such relatively poor attentional control is a bias toward stimulus-driven (or bottom-up attention) that favors selection of CSs for guiding behavior (Koshy Cherian et al., 2017). Such a bias for bottom-up processes also disfavors using cues that require a more elaborative cognitive analysis, such as a $\mathrm{DS}^{+}$that is embedded in the context in which cocaine was initially available (Di Ciano and Everitt, 2003; Trask et al., 2017). Such a bias in STs may be mediated in part via a relatively unresponsive cholinergic system (Paolone et al., 2013) due to frontal cortical choline transporters that fail to accommodate increases in cholinergic neurotransmission with increasing demand (Koshy Cherian et al., 2017). 
Conversely, GTs appear to be better able to process more complex higher-order contextual information such as that afforded by DS because their more responsive cortical cholinergic system facilitates executive/attentional control over behavior (Paolone et al., 2013). Indeed, levels of cortical cholinergic neuromodulation (Sarter and Kim, 2015) scale with the capacity for attentional control (St Peters et al., 2011; Sarter et al., 2016). Partial removal of cholinergic neurons reduces levels of cortical cholinergic neuromodulation and disrupts attentional control capabilities (Ljubojevic et al., 2014), including binding the features of complex stimuli (Turchi and Sarter, 1997; Botly and De Rosa, 2009) and the integration of such stimuli with affectivemotivational states (Wilson and Rolls, 1990; Paolone et al., 2012; Leong et al., 2017). Consistent with this idea, the cholinergic lesion decreased to ability of the $\mathrm{DS}^{+}$to evoke drug-seeking behavior in GTs to the level seen in STs. Therefore, we speculate that cholinergic loss may have largely attenuated the processing of the multiple features of the context necessary to generate a cognitive expectation of reward in GTs and the integration or binding of this context with the (enhanced) motivational state triggered by the $\mathrm{DS}^{+}$in control GTs. However, the precise ways in which the disruption of cholinergic neurotransmission interfered with the many very complex cognitive-motivational interrelations that set the occasion for drug seeking remain to be determined.

\section{Diverse roads to relapse and major research questions}

In the real world, addicts frequently encounter a multitude of stimuli that can promote relapse, including CSs and the more complex contextual cues and occasion setters that signal "drug availability emphasized here," not to mention stressors and other stimuli that influence mood states. Preclinical studies on STs and GTs highlight the fact that different individuals process these different classes of cues in quite different ways both psychologically and neurobiologically and, although research on this factor in humans is nascent, similar variation has been reported (Field and Cox, 2008; Mahler and de Wit, 2010; Marhe et al., 2013; Kilts et al., 2014; Garofalo and di Pellegrino, 2015). The different cognitive-motivational biases leading to different vulnerabilities for relapse emphasized here suggest that different interventions may be required in different individuals and in different situations, including potential cholinergic therapies (Xie et al., 2012). However, much remains to be learned concerning the cognitive-motivational nature of differential vulnerabilities for relapse and also how mesolimbic dopaminergic and basal forebrain cholinergic circuitry interact to mediate the many roads to relapse.

\section{References}

Allain F, Roberts DC, Lévesque D, Samaha AN (2017) Intermittent intake of rapid cocaine injections promotes robust psychomotor sensitization, increased incentive motivation for the drug and $\mathrm{mGlu} 2 / 3$ receptor dysregulation. Neuropharmacology 117:227-237. CrossRef Medline

Bindra D (1968) Neuropsychological interpretation of the effects of drive and incentive-motivation on general activity and instrumental behavior. Psychol Rev 75:1-22. CrossRef

Botly LC, De Rosa E (2009) Cholinergic deafferentation of the neocortex using 192 IgG-saporin impairs feature binding in rats. J Neurosci 29: 4120-4130. CrossRef Medline

Clark JJ, Hollon NG, Phillips PE (2012) Pavlovian valuation systems in learning and decision making. Curr Opin Neurobiol 22:1054-1061. CrossRef Medline

Crombag HS, Badiani A, Maren S, Robinson TE (2000) The role of contextual versus discrete drug-associated cues in promoting the induction of psychomotor sensitization to intravenous amphetamine. Behav Brain Res 116:1-22. CrossRef Medline

Crombag HS, Bossert JM, Koya E, Shaham Y (2008) Context-induced re- lapse to drug seeking: a review. Philos Trans R Soc Lond B Biol Sci 363: 3233-3243. CrossRef Medline

Dar R, Rosen-Korakin N, Shapira O, Gottlieb Y, Frenk H (2010) The craving to smoke in flight attendants: relations with smoking deprivation, anticipation of smoking, and actual smoking. J Abnorm Psychol 119: 248-253. CrossRef Medline

Di Ciano P, Everitt BJ (2003) Differential control over drug-seeking behavior by drug-associated conditioned reinforcers and discriminative stimuli predictive of drug availability. Behav Neurosci 117:952-960. CrossRef Medline

Field M, Cox WM (2008) Attentional bias in addictive behaviors: a review of its development, causes, and consequences. Drug Alcohol Depend 97:120. CrossRef Medline

Flagel SB, Robinson TE (2017) Neurobiological basis of individual variation in stimulus-reward learning. Curr Opin Behav Sci 13:178-185. CrossRef

Flagel SB, Watson SJ, Robinson TE, Akil H (2007) Individual differences in the propensity to approach signals vs goals promote different adaptations in the dopamine system of rats. Psychopharmacology (Berl) 191:599_ 607. CrossRef Medline

Flagel SB, Akil H, Robinson TE (2009) Individual differences in the attribution of incentive salience to reward-related cues: Implications for addiction. Neuropharmacology 56:139-148. CrossRef Medline

Flagel SB, Clark JJ, Robinson TE, Mayo L, Czuj A, Willuhn I, Akers CA, Clinton SM, Phillips PE, Akil H (2011) A selective role for dopamine in stimulus-reward learning. Nature 469:53-57. CrossRef Medline

Garofalo S, di Pellegrino G (2015) Individual differences in the influence of task-irrelevant Pavlovian cues on human behavior. Front Behav Neurosci 9:163. CrossRef Medline

Greenwald AG, Gonzalez R, Harris RJ, Guthrie D (1996) Effect sizes and p values: What should be reported and what should be replicated? Psychophysiology 33:175-183. CrossRef Medline

Kawa AB, Bentzley BS, Robinson TE (2016) Less is more: prolonged intermittent access cocaine self-administration produces incentive-sensitization and addiction-like behavior. Psychopharmacology (Berl) 233:3587-3602. CrossRef Medline

Kilts CD, Kennedy A, Elton AL, Tripathi SP, Young J, Cisler JM, James GA (2014) Individual differences in attentional bias associated with cocaine dependence are related to varying engagement of neural processing networks. Neuropsychopharmacology 39:1135-1147. CrossRef Medline

Koshy Cherian A, Kucinski A, Pitchers K, Yegla B, Parikh V, Kim Y, Valuskova P, Gurnani S, Lindsley CW, Blakely RD, Sarter M (2017) Unresponsive choline transporter as a trait neuromarker and a causal mediator of bottom-up attentional biases. J Neurosci 37:2947-2959. CrossRef Medline

Leong YC, Radulescu A, Daniel R, DeWoskin V, Niv Y (2017) Dynamic interaction between reinforcement learning and attention in multidimensional environments. Neuron 93:451-463. CrossRef Medline

Ljubojevic V, Luu P, De Rosa E (2014) Cholinergic contributions to supramodal attentional processes in rats. J Neurosci 34:2264-2275. CrossRef Medline

Lovic V, Saunders BT, Yager LM, Robinson TE (2011) Rats prone to attribute incentive salience to reward cues are also prone to impulsive action. Behav Brain Res 223:255-261. CrossRef Medline

Mahler SV, de Wit H (2010) Cue-reactors: individual differences in cueinduced craving after food or smoking abstinence. PLoS One 5:e15475. CrossRef Medline

Marhe R, Luijten M, van de Wetering BJ, Smits M, Franken IH (2013) Individual differences in anterior cingulate activation associated with attentional bias predict cocaine use after treatment. Neuropsychopharmacology 38:1085-1093. CrossRef Medline

Meyer PJ, Lovic V, Saunders BT, Yager LM, Flagel SB, Morrow JD, Robinson TE (2012) Quantifying individual variation in the propensity to attribute incentive salience to reward cues. PLoS One 7:e38987. CrossRef Medline

Meyer PJ, Cogan ES, Robinson TE (2014) The form of a conditioned stimulus can influence the degree to which it acquires incentive motivational properties. PLoS One 9:e98163. CrossRef Medline

Milton AL, Everitt BJ (2010) The psychological and neurochemical mechanisms of drug memory reconsolidation: implications for the treatment of addiction. Eur J Neurosci 31:2308-2319. CrossRef Medline

Morrow JD, Maren S, Robinson TE (2011) Individual variation in the propensity to attribute incentive salience to an appetitive cue predicts the 
propensity to attribute motivational salience to an aversive cue. Behav Brain Res 220:238-243. CrossRef Medline

Paolone G, Lee TM, Sarter M (2012) Time to pay attention: attentional performance time-stamped prefrontal cholinergic activation, diurnality, and performance. J Neurosci 32:12115-12128. CrossRef Medline

Paolone G, Angelakos CC, Meyer PJ, Robinson TE, Sarter M (2013) Cholinergic control over attention in rats prone to attribute incentive salience to reward cues. J Neurosci 33:8321-8335. CrossRef Medline

Paxinos G, Watson C (2007) The rat brain in stereotaxic coordinates, Ed 6. San Diego: Academic.

Pitchers KK, Flagel SB, O'Donnell EG, Woods LC, Sarter M, Robinson TE (2015) Individual variation in the propensity to attribute incentive salience to a food cue: influence of sex. Behav Brain Res 278:462-469. CrossRef Medline

Pitchers KK, Wood TR, Skrzynski CJ, Robinson TE, Sarter M (2017) The ability for cocaine and cocaine-associated cues to compete for attention. Behav Brain Res 320:302-1315. CrossRef Medline

Rescorla RA (1988) Pavlovian conditioning: it's not what you think it is. Am Psychol 43:151-160. CrossRef

Robinson TE, Berridge KC (1993) The neural basis of drug craving: an incentive-sensitization theory of addiction. Brain Res Rev 18:247-291. CrossRef Medline

Robinson TE, Yager LM, Cogan ES, Saunders BT (2014) On the motivational properties of reward cues: Individual differences. Neuropharmacology 76:450-459. CrossRef Medline

Rowland NE (2007) Food or fluid restriction in common laboratory animals: balancing welfare considerations with scientific inquiry. Comp Med 57:149-160. Medline

Sarter M, Fritschy JM (2008) Reporting statistical methods and statistical results in EJN. Eur J Neurosci 28:2363-2364. CrossRef Medline

Sarter M, Kim Y (2015) Interpreting chemical neurotransmission in vivo: techniques, time scales, and theories. ACS Chem Neurosci 6:8-10. CrossRef Medline

Sarter M, Lustig C, Blakely RD, Koshy Cherian A (2016) Cholinergic genetics of visual attention: Human and mouse choline transporter capacity variants influence distractibility. J Physiol Paris 110:10-18. CrossRef Medline

Saunders BT, Robinson TE (2010) A cocaine cue acts as an incentive stimulus in some but not others: implications for addiction. Biol Psychiatry 67:730-736. CrossRef Medline

Saunders BT, Robinson TE (2011) Individual variation in the motivational properties of cocaine. Neuropsychopharmacology 36:1668-1676. CrossRef Medline

Saunders BT, Robinson TE (2012) The role of dopamine in the accumbens core in the expression of Pavlovian-conditioned responses. Eur J Neurosci 36:2521-2532. CrossRef Medline

Saunders BT, Yager LM, Robinson TE (2013) Cue-evoked cocaine "craving": role of dopamine in the accumbens core. J Neurosci 33:1398914000. CrossRef Medline
Saunders BT, O’Donnell EG, Aurbach EL, Robinson TE (2014) A cocaine context renews drug seeking preferentially in a subset of individuals. Neuropsychopharmacology 39:2816-2823. CrossRef Medline

Shaham Y, Adamson LK, Grocki S, Corrigall WA (1997) Reinstatement and spontaneous recovery of nicotine seeking in rats. Psychopharmacology (Berl) 130:396-403. CrossRef

Singer BF, Bryan MA, Popov P, Scarff R, Carter C, Wright E, Aragona BJ, Robinson TE (2016) The sensory features of a food cue influence its ability to act as an incentive stimulus and evoke dopamine release in the nucleus accumbens core. Learn Mem 23:595-606. CrossRef Medline

St Peters M, Demeter E, Lustig C, Bruno JP, Sarter M (2011) Enhanced control of attention by stimulating mesolimbic-corticopetal cholinergic circuitry. J Neurosci 31:9760-9771. CrossRef Medline

Toates F (1998) The interaction of cognitive and stimulus-response processes in the control of behaviour. Neurosci Biobehav Rev 22:59-83. Medline

Trask S, Thrailkill EA, Bouton ME (2017) Occasion setting, inhibition, and the contextual control of extinction in Pavlovian and instrumental (operant) learning. Behav Processes 137:64-72. CrossRef Medline

Turchi J, Sarter M (1997) Cortical acetylcholine and processing capacity: effects of cortical cholinergic deafferentation on crossmodal divided attention in rats. Brain Res Cogn Brain Res 6:147-158. CrossRef Medline

Weiss F (2005) Neurobiology of craving, conditioned reward and relapse. Curr Opin Pharmacol 5:9-19. CrossRef Medline

Weiss F, Maldonado-Vlaar CS, Parsons LH, Kerr TM, Smith DL, Ben-Shahar O (2000) Control of cocaine seeking behavior by drug-associated stimuli in rats: effects on recovery of extinguished operant-responding and extracellular dopamine levels in amygdala and nucleus accumbens. Proc Natl Acad Sci U S A 97:4321-4326. CrossRef Medline

West BT, Welch KB, Galecki AT (2006) Linear mixed models: a practical guide using statistical software, Ed 1. New York: Taylor and Francis.

Wilson FA, Rolls ET (1990) Learn Mem is reflected in the responses of reinforcement-related neurons in the primate basal forebrain. J Neurosci 10:1254-1267. Medline

Xie X, Arguello AA, Reittinger AM, Wells AM, Fuchs RA (2012) Role of nicotinic acetylcholine receptors in the effects of cocaine-paired contextual stimuli on impulsive decision making in rats. Psychopharmacology (Berl) 223:271-279. CrossRef Medline

Yager LM, Robinson TE (2013) A classically conditioned cocaine cue acquires greater control over motivated behavior in rats prone to attribute incentive salience to a food cue. Psychopharmacology (Berl) 226:217228. CrossRef Medline

Yager LM, Pitchers KK, Flagel SB, Robinson TE (2015) Individual variation in the motivational and neurobiological effects of an opioid cue. Neuropsychopharmacology 40:1269-1277. CrossRef Medline

Zimmer BA, Oleson EB, Roberts DC (2012) The motivation to selfadminister is increased after a history of spiking brain levels of cocaine. Neuropsychopharmacology 37:1901-1910. CrossRef Medline 